Nota

\title{
COR DE FEIJÃO VAGEM FRESCO E PROCESSADO APÓS APLICAÇÃO DE CÁLCIO'
}

\author{
Simone Palma Fávaro²*; Marcela Colognesi de Sá3; Elza louko Ida4; José Antônio Braga Neto ${ }^{5}$ \\ ${ }^{2}$ Centro de Ciências Biológicas e da Saúde - Universidade Católica Dom Bosco, C.P. 100 - CEP: 79117-0101 - \\ Campo Grande, MS. \\ ${ }^{3}$ Depto. Tecnologia de Alimentos - Universidade Federal de Mato Grosso do Sul, C.P. 649 - CEP: 79100-000 - \\ Campo Grande, MS. \\ ${ }^{4}$ Depto. Tecnologia de Alimentos e Medicamentos - UEL, C.P. 6001 - CEP: 86051-970 - Londrina, PR. \\ ${ }^{5}$ Bolsista de Iniciação Científica - UEL. \\ *Autor correspondente <braga@nin.ufms.br>
}

RESUMO: A cor em vegetais é um dos principais atributos de qualidade observado pelo consumidor e é influenciada por características intrínsecas e de processamento. O objetivo desta investigação foi avaliar as alterações de cor de feijão vagem fresco e processado após aplicação de concentrações crescentes de cálcio via absorção radicular. O feijão vagem cultivar UEL 1 foi cultivado com aplicação de concentrações crescentes de cálcio via solução nutritiva contendo 0, 75, 150 e $300 \mathrm{~mL} \mathrm{~L}^{-1}$ de cálcio em substrato de areia grossa. A cor das vagens ao natural e enlatadas foram avaliadas por colorimetria de três estímulos, e os resultados foram expressos no sistema Hunter. As vagens ao natural apresentaram-se mais claras e amarelas quando foi adicionado cálcio à solução nutritiva. O calor empregado no processo de enlatamento teve efeito pronunciado na redução da luminosidade e na cor verde, mesmo com o aumento na quantidade de cálcio nas vagens.

Palavras-chave: Phaseolus vulgaris, feijão-vagem, cor, cálcio

\section{COLOR OF FRESH AND PROCESSED SNAP BEAN PODS AFTER CALCIUM APPLICATION}

\begin{abstract}
The color in vegetables is one of the main quality attributes observed by the consumer and it is influenced by intrinsic characteristics and canning process. This research meant to investigate the effect of increasing calcium concentrations applied to a nutrient solution on physical measurements of the color of snap bean pods. This experiment was carried out wtih the cultivar UEL 1 grown in coarse sand with nutrient solution supplied at the following levels of calcium: $0,75,150$ and $300 \mathrm{~mL} \mathrm{~L}^{-1}$. Fresh pods were analysed for calcium content. The fresh and canned pods were evaluated for color with tristimulus colorimetry and data were expressed according to the Hunter system. The fresh pods were lighter and yellowisher when calcium was added to the nutrient solution. The heat used for the canning process had a significant effect on reducing lightness and greeness, even with the greater amounts of calcium in the pods.
\end{abstract}

Key words: Phaseolus vulgaris, snap beans, color, calcium

\section{INTRODUÇÃO}

A manutenção de coloração natural de hortaliças é muito importante após o seu processamento. A identificação como um produto fresco aumenta a aceitabilidade do consumidor. No caso de feijão vagem, os pigmentos responsáveis pela cor característica de verde brilhante, são as clorofilas a e b (Fennema, 1988). Durante o processamento de vegetais, em especial com a aplicação de calor, podem ocorrer transformações na molécula de clorofila com alterações da coloração verde brilhante. A modificação mais comum é a substituição do íon magnésio, ligado ao anel pirrólico da clorofila, por íons hidrogênio formando a feofitina, que confere uma coloração verde-oliva escura e opaca (Hayakawa, 1977).

Os íons cálcio são essenciais na manutenção da integridade de membrana e parede celulares e conseqüen- temente, estão relacionados com a manutenção dos atributos de qualidade de vegetais processados e frescos (Van Buren, 1980). Adicionando cálcio em maçã (Glenn \& Poovaiah, 1988), observaram maior conteúdo de clorofila nos frutos, enquanto que o cultivo de tomate com $160 \mathrm{ppm}$ de cálcio resultou em maior teor de clorofilas totais das folhas (Oyewole \& Aduayi, 1992).

Alterações na cor de produtos vegetais podem ser avaliadas por meio de determinações químicas, quantificando o teor de pigmentos ou por meio de medidas físicas. Denomina-se colorimetria aos métodos onde se aplicam as propriedades de absorção e transmissão da luz e a conversão desta energia, via filtros apropriados ou modelos matemáticos, em valores com significado em termos de percepção visual (Clydesdale, 1984). Para o feijão vagem, foi encontrada uma boa correlação entre medidas físicas de cor pelo sistema Hunter e a

${ }^{1}$ Traballho apresentado no $25^{\circ}$ Congresso Brasileiro de Ciência e Tecnologia de Alimentos, Poços de Caldas, 1996.

Scientia Agricola, v.57, n.3, p.561-563, jul./set. 2000 
quantificação de clorofilas e feofitinas, sugerindo-se que ambos os métodos seriam satisfatórios para verificar alterações na cor (Moojen, 1986).

O objetivo deste trabalho foi investigar as alterações de cor de feijão vagem ao natural e processado após aplicação de concentrações crescentes de cálcio via absorção radicular.

\section{MATERIAL E MÉTODOS}

Foi utilizado neste experimento o feijão vagem (Phaseolus vulgaris) cultivar UEL 1, desenvolvido pelo Departamento de Agronomia da Universidade Estadual de Londrina, Paraná. Este genótipo caracteriza-se pela alta produtividade, precocidade e apresenta vagens cilíndricas (Castiglioni et al., 1993).

Para o desenvolvimento vegetal, considerou-se como adequado o intervalo de $120 \mathrm{a} 160 \mathrm{~mL} \mathrm{~L}^{-1}$ de cálcio (Milikan et al., 1971). Como não se encontraram dados específicos ao feijão vagem em relação a níveis superior e inferior ao estudado, utilizaram-se os tratamentos contendo as seguintes concentrações de cálcio: 0, 75, 150 e $300 \mathrm{~mL}$ $\mathrm{L}^{-1}$ aplicadas em solução nutritiva descrita por Sarruge (1975).

O ensaio foi conduzido em casa de vegetação em vasos de cerâmica com capacidade para cinco litros, contendo como substrato areia grossa que possuía teor inicial de $80 \mathrm{~mL} \mathrm{~L}^{-1}$ de cálcio. Foram estabelecidas duas plantas por vaso. Em cada vaso foi adicionado um litro de solução nutritiva por semana e diariamente a solução percolada era coletada em frascos âmbar, completada para um litro com água e reposta nos vasos. A cada sete dias a solução nutritiva foi renovada, fazendo-se uma lavagem prévia do substrato com dois litros de água destilada em cada vaso. Toda água empregada no experimento era destilada e não continha traços de cálcio, conforme controle realizado por espectrofotometria de absorção atômica.

Para processamento, utilizaram-se $130 \mathrm{~g}$ de vagens cortadas em pedaços de $9 \mathrm{~cm}$ que foram branqueadas a $76^{\circ} \mathrm{C}$ por 4 minutos (Van Buren, 1973), seguido de resfriamento em banho de gelo e acondicionadas em latas de folhas de flandres contendo salmoura $(\mathrm{NaCl} 1,5 \%)$. A esterilização procedeu-se por autoclavagem a $116^{\circ} \mathrm{C}$ por 20 minutos e resfriamento em água corrente.

As medidas de cor foram efetuadas pCor colorimetria de três estímulos, utilizando-se espectrofotômetro (Hitachi, Modelo U-4310), com acessório de esfera de integração, empregando-se programa para determinação da cor pelo sistema C.I.E./ $L^{*} a^{*} b^{*}$. As condições de operação do equipamento foram: varredura de $780-380 \mathrm{~nm}$, velocidade de varredura de $120 \mathrm{~nm} \mathrm{~min}{ }^{-1}$ e iluminante $C$. As médias obtidas foram expressas pelo sistema Hunter (Clydesdale, 1984) com os índices $L$, a e b. L indica Luminosidade, valores negativos de a referem-se à intensidade da cor verde e valores positivos indicam a cor marrom e b relaciona-se à cor amarela. Dos dados obtidos foram calculadas as razões -a/b das vagens frescas indicando a tendência à cor verde.
Foi aplicado o delineamento experimental inteiramente casualizado, com cinco repetições de cada tratamento e dez vasos por repetição, totalizando duzentas unidades. Aplicou-se o teste de Tukey a 5\% para comparação das médias de tratamentos. As médias foram analisadas empregando-se o programa SAS (SAS Institute, 1989). Os dados que não se ade-quaram aos pressupostos da análise de variância foram comparados por testes de estatística não-paramétrica, utilizando programa desenvolvido por Negrillo et al. (1993).

\section{RESULTADOS E DISCUSSÃO}

Os teores de cálcio determinados nas vagens frescas, submetidas aos tratamentos, foram apresentados por Fávaro \& Ida (1998). A adição de maiores doses de cálcio à solução nutritiva conferiu um aumento significativo no teor deste mineral nas vagens. As vagens cultivadas com solução isenta de cálcio apresentaram teor médio de

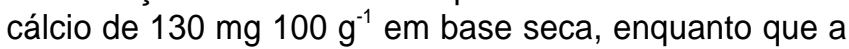
adição de $300 \mathrm{~mL} \mathrm{~L}^{-1}$ de cálcio elevou este valor para 520 $\mathrm{mg}$, ou seja um incremento da ordem de quatro vezes. Quintana et al. (1999) identificaram concentrações que variaram de 350 a $650 \mathrm{mg}$ de cálcio $100 \mathrm{~g}^{-1}$ de matéria seca de vagens em diferentes genótipos, cultivados em condições de campo.

As medidas de cor em feijão vagem fresco cultivado com concentrações crescentes de cálcio foram expressas através do sistema Hunter e estão apresentadas na TABELA 1. As médias da variável $L$ foram comparadas pelo teste de Tukey, enquanto que para os valores de -a, b e -a/b aplicou-se a estatística não paramétrica. As medidas de luminosidade (L) foram semelhantes estatisticamente entre os tratamentos 75,150 e $300 \mathrm{~mL}$ $\mathrm{L}^{-1}$ de cálcio e estas doses diferiram significativamente do tratamento isento de cálcio. Assim, as vagens cultivadas com adição de cálcio à solução nutritiva apresentaram luminosidades crescentes com os incrementos de cálcio à solução nutritiva.

As medidas de valores negativos de a não diferiram significativamente entre as concentrações de cálcio adicionadas ao feijão vagem, demonstrando que não houve diferença quanto à intensidade da cor verde.

Para os valores de $b$, a análise estatística evidenciou diferença significativa entre as vagens cultivadas com solução isenta de cálcio e os demais tratamentos. Esta resposta demonstrou que a aplicação de cálcio na solução nutritiva conferiu maior intensidade da cor amarela às vagens frescas.

Sistrunk (1969) descreveu que a manutenção da cor verde é importante para assegurar o parâmetro de qualidade de alguns produtos. A intensidade da coloração esverdeada das vagens foi medida pelas médias da relação. Houve diferença em nível de $5 \%$ de significância entre os tratamentos que receberam 0 e $300 \mathrm{~mL} \mathrm{~L}^{-1}$ de cálcio (TABELA 1). Em módulo, a aplicação de $300 \mathrm{~mL} \mathrm{~L}^{-1}$ de cálcio apresentou resultado inferior em relação ao 
tratamento isento de cálcio, indicando maior tendência à cor esverdeada nas vagens com menor concentração de cálcio.

As médias dos valores de $L$, $a$ e $b$ das vagens processadas estão descritas na TABELA 2. O teste de Tukey foi aplicado à variável $L$ e as demais variáveis foram submetidos a testes de estatística não paramétrica. As vagens processadas apresentaram valores positivos para a medida de a, por este motivo não foi calculada a razão -a/b. As respostas das medidas de cor $L$, a e b, após o processamento térmico, não apresentaram diferença significativa em função das concentrações de cálcio adicionadas à solução de cultivo. O processamento resultou em vagens com perda da coloração verde brilhante, tornando-as verde oliva, o que foi demonstrado por valores mais altos de $b$ e pelos valores positivos de a. As vagens adquiriram também maior opacidade com redução nos valores de $L$ em relação às vagens frescas (TABELA 1). Estas alterações são características da reação de feofitinização das clorofilas (Hayakawa, 1977) e também foram observadas em outras cultivares de feijão vagem (Collins \& Mollins, 1984). O acréscimo significativo do teor de cálcio nas vagens após aplicação de calor não resultou na manutenção da cor verde característica.

TABELA 1 - Medidas de cor pelo sistema Hunter $(\mathrm{L}=$ luminosidade, $-\mathrm{a}=$ intensidade da cor verde, $\mathrm{b}=$ intensidade da cor amarela $\mathrm{e}-\mathrm{a} / \mathrm{b}=$ tendência à cor verde) em feijão vagem ao natural cultivado com concentrações crescentes de cálcio.

\begin{tabular}{ccccc}
\hline Tratamentos & $\mathrm{L}^{*}$ & $-\mathrm{a}^{* *}$ & \multicolumn{1}{c}{$\mathrm{b}^{* *}$} & $-\mathrm{a} / \mathrm{b}^{* *}$ \\
\hline $\mathrm{mL} \mathrm{L}{ }^{-1}$ cálcio & & & & \\
0 & $47,58 \mathrm{~b}$ & $3,88 \mathrm{a}$ & $7,48 \mathrm{~b}$ & $0,52 \mathrm{a}$ \\
75 & $50,89 \mathrm{a}$ & $4,80 \mathrm{a}$ & $10,18 \mathrm{a}$ & $0,47 \mathrm{ba}$ \\
150 & $52,07 \mathrm{a}$ & $4,96 \mathrm{a}$ & $10,87 \mathrm{a}$ & $0,46 \mathrm{ba}$ \\
300 & $53,47 \mathrm{a}$ & $5,30 \mathrm{a}$ & $11,94 \mathrm{a}$ & $0,44 \mathrm{~b}$ \\
\hline CV (\%) & 3,46 & 14,63 & 16,72 & 48,07 \\
\hline
\end{tabular}

*Letras distintas na vertical indicam diferença significativa pelo teste de Tukey $(\mathrm{P}<0,05)$ para dados com distribuição normal.

**Letras distintas na vertical indicam diferença significativa a $5 \%$ pela análise não-paramétrica.

TABELA 2 - Medidas de cor pelo sistema Hunter Hunter $(L=$ luminosidade, $\mathrm{a}=$ intensidade da cor marrom, $b=$ intensidade da cor amarela) em feijãovagem processado cultivado com concentrações crescentes de cálcio.

\begin{tabular}{|c|c|c|c|}
\hline Tratamentos & $L^{*}$ & $a^{* *}$ & $b^{* *}$ \\
\hline \multicolumn{4}{|l|}{$\mathrm{mL} \mathrm{L}^{-1}$ cálcio } \\
\hline 0 & $41,52 \mathrm{a}$ & $0,91 \mathrm{a}$ & $12,27 \mathrm{a}$ \\
\hline 75 & $40,31 \mathrm{a}$ & $1,64 \mathrm{a}$ & $11,83 \mathrm{a}$ \\
\hline 150 & $41,38 \mathrm{a}$ & $1,25 a$ & $12,23 a$ \\
\hline 300 & $44,11 \mathrm{a}$ & $0,86 \mathrm{a}$ & $11,83 \mathrm{a}$ \\
\hline $\mathrm{CV}(\%)$ & 5,11 & 59,86 & 16,64 \\
\hline
\end{tabular}

*Letras distintas na vertical indicam diferença significativa pelo teste de Tukey $(P<0,05)$ para dados com distribuição normal.

** Letras distintas na vertical indicam diferença significativa pela análise não-paramétrica $(\mathrm{P}<0,05)$.

\section{AGRADECIMENTOS}

Ao CNPq pela Bolsa de Mestrado concedida a Fávaro, S. e aos recursos liberados para o projeto, ao Dr. José Alfredo Areas pelo uso do espectrofotômetro da FCF/ USP e à Profa. Tiemi Matsuo (Depto. Matemática Aplicada/ UEL) pela colaboração nas análises estatísticas.

\section{REFERÊNCIAS BIBLIOGRÁFICAS}

CASTIGLIONI, F.V.B.R.; TAKAHASHI, L.S.A.; ATHANAZIO, J.C.; MENEZES, J.R.; Fonseca, M.A.; Castilho, S.R. "UEL 1": nova cultivar de feijão-vagem com hábito de crescimento determinado. Horticultura Brasileira, v.11, p.164, 1993.

CLYDESDALE, F.M. Color measurement. In:GRUENWEDEL, D.W.; WHITAKER, J.R.(Ed.) Food analysis: principles and techniques. New York: Marcel Dekker, 1984. v.1, p.95-150.

COLLINS, J.L.; MOLLINS, C.A. Tennessee snap beans for canning and freezing. Tennessee Farm and Home Science, v.130, p.11-14, 1984.

FÁVARO, S.; IDA, E.I. Textura de feijão vagem (Phaseolus vulgaris L.) processado ou não: efeito da aplicação de concentrações crescentes de cálcio via absorção radicular. Ciência e Tecnologia de Alimentos, v.18, p.188-192, 1998.

FENNEMA, O.R. Introducción a la ciencia de los alimentos. Barcelona: Reverté, 1988. 918p.

GLENN, G.M.; POOVAIAH, B.W. Effect of calcium on cell wall structure, protein phosphorylation and protein profile in senescing apples. Plant Cell Physiology, v.29, p.565-572, 1988.

HAYAKAWA, K.-I. Influence of heat treatment on the quality of vegetables: changes in visual green color. Journal of Food Science, v.42, p.778-781, 1977.

MILIKAN, C.R.; BJARNASON, E.N.; OSBORN, R.K.; HANGER, B.C. Calcium concentration in tomato fruits in relation to the incidence of blossom-end-rot. Australian Journal of Experimental and Animal Husbandry, v.11, p.570-575, 1971. MOOJEN, D.L. Efeito de cálcio, magnésio e cobre, adicionados à água de branqueamento, na retenção da cor verde em figos e vagens termoprocessados. Viçosa, 1986. 80p. Dissertação (M.S.) - Universidade Federal de Viçosa.

NEGRILLO, B.G.; SARRIES, G.A; ZACARIAS, M.; ALVES, M.C.; OLIVEIRA, J.C.V. SENP - Sistema de estatística nãoparamétrica. Piracicaba: CIAGRI/USP, 1993.

OYEWOLE, O.I.; ADUAYI, E.A. Evaluation of the growth and quality of the "ife plum" tomato as affcted by boron and calcium fertilization. Journal of Plant Nutrition, v.15, p.199-209, 1992.

QUINTANA, J.M.; HARRISON, H.C.; NIENHUIS, J.; PALTA, J.P.; KMIECIK, K.; MIGLIORANZA, E. Comparison of pod calcium concentration between two snap bean populations. Journal of the American Society for Horticultural Science, v.124, p.273-276, 1999.

SARRUGE, J.R. Soluções nutritivas. Summa Phytopathologica, v.1, p.231-133, 1975.

SISTRUNK, W.A. Differentiation between varieties of bush beans by chemical and physical methods. Food Techonology, v.23, p.80-83, 1969.

SAS INSTITUTE. SAS/STAT user's guide. 4.ed. Cary: Statistical Analysis System Institute,1989. v.2.

VAN BUREN, J.P. Improved firmness without additives. Food Engineering, v.45, p.127, 1973.

VAN BUREN, J.P. Calcium binding to snap bean waterinsoluble solids: calcium and sodium concentrations. Journal of Food Science, v.45, p.752-753, 1980. 